\title{
KEEPING A LID ON OPEN SCIENCE
}

\author{
Efforts to promote and \\ enforce shared research have \\ made progress in China, \\ but there is much room \\ for improvement.
}

\section{BY HEPENG JIA}

cientists in China have for years shown
a willingness to embrace the principles of open science. The country hosted the major international open science conference, CODATA, in 1992, and again in 2006. China's largest research organization, the Chinese Academy of Sciences (CAS), and the major science funding agency, the National Natural Science Foundation of China (NSFC), were also early signatories to the 2003 Berlin Declaration on Open Access to Knowledge in the Sciences and Humanities. Signatories agree that research should be made freely available online to all.

But, despite these signs, advocates of openness are frustrated by progress over the past decade. They say the country's rigid publication regulations and information control, including the internet firewall which prevents researchers using some social media platforms to share information with international peers and the public, are partly to blame. Some also point to weak leadership and inadequate policies emanating from key government agencies such as the Ministry of Science and Technology (MOST) and the Ministry of Education. While initiatives designed to promote open science exist, Wu Yishan, former deputy director general of the Institute of Scientific and Technical Information of China (ISTIC) and an active science policy researcher, says "the advances of open science initiatives are less than satisfactory".

"We need strong leadership to promote this enterprise." 

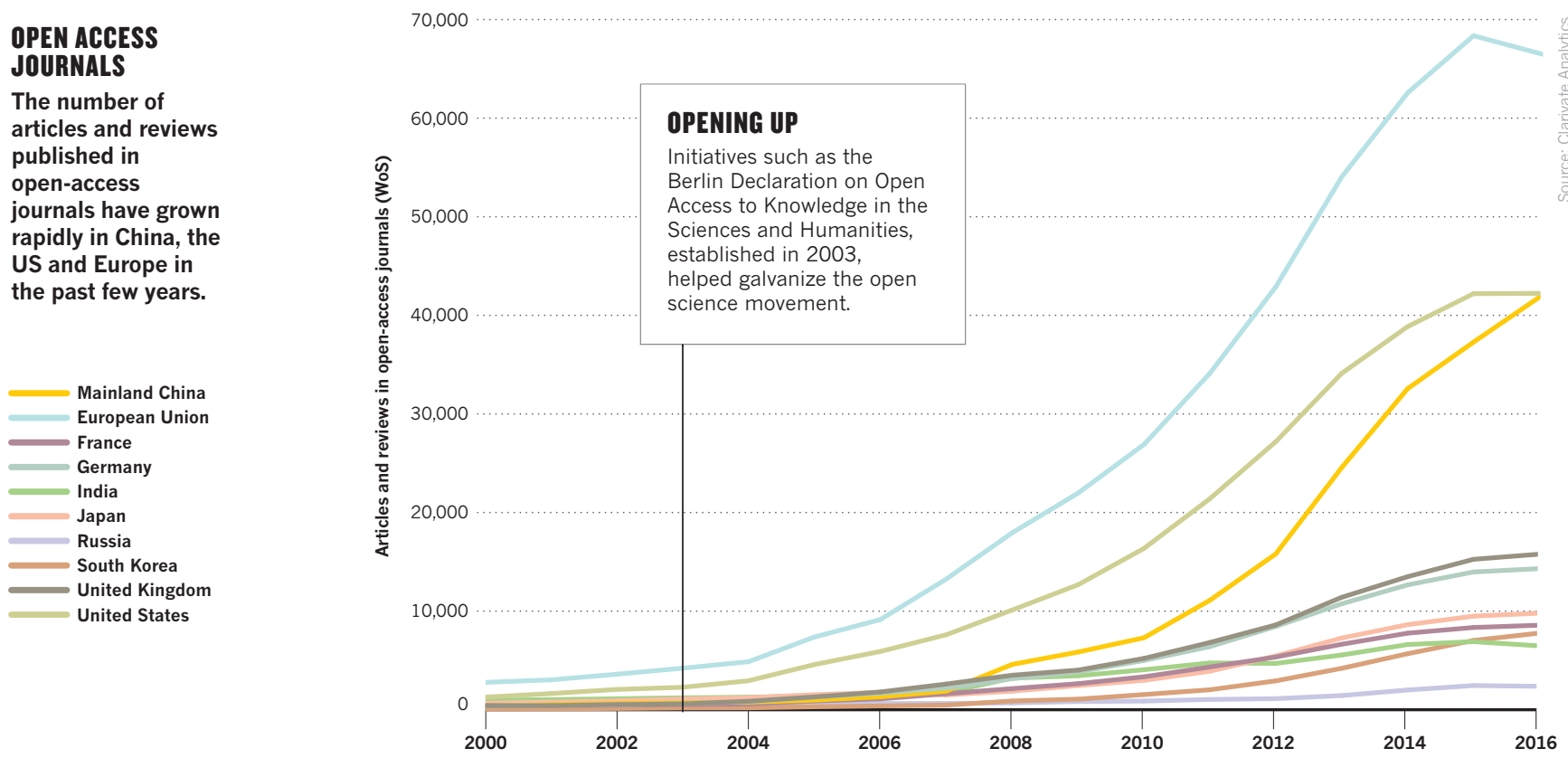

Open science, a loosely defined term, promotes practices such as open-access (OA) publishing, preprint archives and freely accessible institutional repositories where researchers deposit their research data for others to access. Judging research impact by more than just citations - for instance, by the level of social media sharing - has also become part of the movement.

\section{TIGHT PUBLISHING CONTROL}

In China, open-access publishing has developed quickly since the mid-2000s. While there are no national statistics on the total numbers of these publications, a 2014 paper authored by Zhang Xiaolin, former director of the National Science Library (NSL) affiliated with CAS and a vocal advocate of open-access publishing, found 180 journals published by CAS have become openly accessible, accounting for half of the journals published by the Academy. Separately, since late 2013, national science and technology associations - which are affiliated with the China Association for Science and Technology (CAST) - have produced 364 open-access journals, accounting for $35 \%$ of their publications. Some Chinese open-access publishers, such as Baishideng Publishing Group, which focus on clinical journals, have also achieved significant commercial success. The company increased from two publications in 2008 to 43 peer-reviewed, open-access journals in clinical medicine, biochemistry and molecular biology last year.

But the government's tight control over publishers has created issues for the domestic open-access market. For instance, an advantage of open-access journals published only online is that publishers save on printing costs. In China, however, most journals and magazines need permission from the government to publish, and they require all materials be printed. As a result, open-access journals incur higher production costs because they often provide their online editions for free, while also bearing the cost of printing, says Wu.

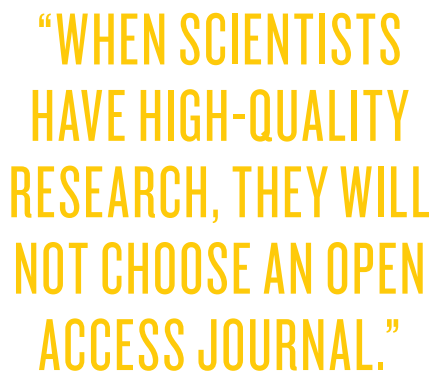

Ren Shengli, editor-in-chief of the journal China Science Foundation, affiliated to the NSFC, said the copyright arrangements of some open-access journals which prevent material being reproduced by others had also deterred scientists from publishing in them. Open-access publications outside China typically have licensing arrangements, such as creative commons, which allow material to be shared and reproduced with appropriate attribution.

China's domestic open-access industry may have issues to overcome, but Chinese scientists have become significant contributors to global open-access journals. Last year Chinese scientists published 41,848 articles in open-access journals indexed in the Web of Science, up from 377 papers in 2000.

\section{HIGH IMPACT PARAMOUNT}

Despite this rise, evidence suggests these papers may not be contributing to an increase in quality papers. A study by Wang Yufang, a senior researcher at the Fudan University Library in Shanghai, found that although Fudan University scientists are publishing increasing numbers of papers in open-access journals each year, these have not contributed to the growth in the average number of citations per scientist. The study found the same was true for researchers at Harvard University.

Wang says that when a Chinese scientist believes they have a top paper, they are likely to submit to a journal with a high-impact factor, most of which are not open access and do not charge author fees.

"The most crucial criterion for citation is paper quality. When scientists have highquality research, they will not choose an OA journal," she said.

Though librarians often promote and support open-access publishing, Wang says they still cost universities a lot of money because scientists pay author fees to publish in these journals. "The total amount scientists at Fudan University paid to publish in OA journals exceeded the amount of money the library paid for journal subscriptions," she said.

Another frustration of Wang's is that some open-access journals are included in databases such as ScienceDirect or Wiley that 

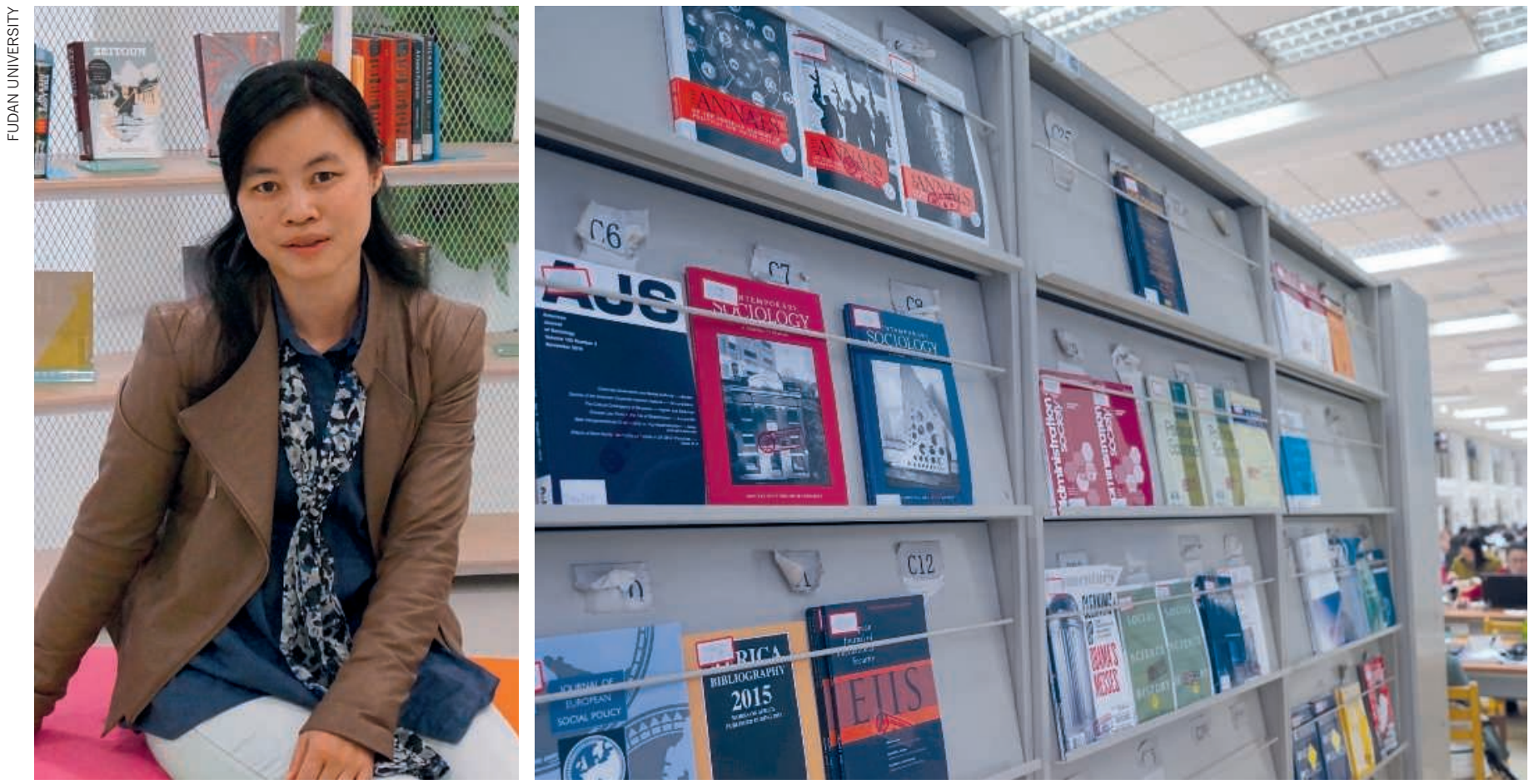

Wang Yufang, at the Fudan University Library, who studied the publishing patterns of researchers, found that Chinese scientists are reluctant to publish their best papers in open-access journals.

universities are required to pay for, despite scientists paying author fees for those articles to be published.

\section{INSTITUTIONAL REPOSITORIES}

For supporters of open science, recent enthusiasm for freely accessible institutional repositories has been a step in the right direction. Researchers at universities and institutes with smaller budgets for journal subscriptions than top Peking, Tsinghua or Fudan universities or CAS are particularly supportive of such repositories. "It may help us to access more unavailable literature," says Lu Jie, an associate professor of high-energy physics at Shanghai University.

In 2014, CAS and NSFC announced that researchers they funded should upload their papers into publicly accessible online repositories within 12 months of publication. Two years later, however, many universities are yet to set up repositories, and where they do exist, many scientists neglect to put their papers up. The global directory of open- access repositories, OpenDOAR, links to only 22 Chinese institutions that have repositories.

"The impact of such repositories is limited due to the lack of involvement by Chinese universities, which account for the majority of Chinese science and technology publications," Ren says. Even within CAS, many scientists are reluctant to upload their papers into institutional repositories because of the paperwork or fear of potential copyright disputes with journal publishers. Despite the CAS and NSFC policies, "no punitive measures are available to ensure the implementation," Wu says.
Some institutions, such as the Institute of Science and Technology Information of China, have stipulated that only publications self-archived into their internal repositories can be accepted for career assessment or promotion. "This type of effective measure can be copied [by other institutions], as long as there is a strong leadership to promote openaccess measures at an institutional level," says $\mathrm{Wu}$. But for open science practices to become

\section{"ALTMETRIC DOES PLAY AN ACTIVE ROLE IN PROMOTING OPEN SCIENCE IN CHINA."}

widespread in China, the government's science leaders have to attach more importance to these issues, he says.

Another initiative to promote open science in China is the country's new preprint database, ChinaXiv, launched by the NSL in 2016. ChinaXiv is similar to arXiv.org, widely used by physicists, but open to scientists publishing in all fields.

At its launch, Wang Keqiang, deputy secretary-general of CAS, stressed ChinaXiv's significance to China, saying it created a transparent environment for academic exchange, prioritized scientific discovery over publication and hastened publication time. But several Chinese physicists, who regularly check new postings in arXiv.org, were unaware of the new database when queried by Nature Index. "arXiv.org has offered both the newest research advances of peers and necessary credibility. I see no urgency for me to try another preprint service only because of its national affiliation," says Wu Huichun, a professor of physics at the prestigious Zhejiang University.

Obstacles to open science in China are not solely down to the scientific community. The country's internet firewall is a major blockage for scientists eager to share their work. For instance, a growing trend to gauge the impact of scholarly work is to measure references to a paper in news reports and reactions on social media, through platforms such as Altmetric. But this requires access to Google, Facebook, Twitter and other blocked sites.

Although the platform's owner, Digital Science, has incorporated into its metrics algorithm, Weibo, the Chinese equivalent of Twitter, Li Yan, a Wiley editor, said few Chinese scientists are active on it. "Altmetric is a valuable tool to track the scholarly influence of a paper beyond the impact factor, and it does help promote open science in China," he says.

Scientists are finding their own ways around the problem. Many use the instant messaging app, WeChat, to read and share links to papers. Even with this work-around, Chinese science still has a long way to go before it fully embraces open science. 